\title{
Brote de rubéola en Chile, 2007
}

DORIS GALLEGOS ${ }^{(1)}$, ANDREA OLEA $^{(2)}$, VIVIANA SOTOMAYOR ${ }^{(3)}$, CLAUDIA GONZÁLEZ $^{(3)}$, JUAN CARLOS MUÑOZ $^{(4)}$, MÓNICA RAMOS ${ }^{(5)}$, SERGIO ALCAYAGA ${ }^{(6)}$, GRACIELA TORRES ${ }^{(7)}$, EMILIO ESPIÑEIRA ${ }^{(8)}$, WINSTON ANDRADE ${ }^{(9)}$, JORGE FERNÁNDEZ $^{(10)}$ y RODRIGO FASCE ${ }^{(11)}$

\section{RESUMEN}

La rubéola es una enfermedad benigna que se transforma en un problema de salud pública cuando afecta a mujeres embarazadas, pudiendo causar graves problemas al feto si llega a desarrollar el Síndrome de Rubéola Congénita (SRC). Para evitar esto, las mujeres de nuestro país entre 10 y 29 años, fueron protegidas en la campaña de vacunación del año 1999 con un 99\% de cobertura; momento en el cual el país se veía enfrentado a un brote de rubéola.

La vacuna trivírica se introdujo en Chile en 1990; posterior a ello, la tendencia de la enfermedad fue al descenso hasta los años 199798, cuando se produce un brote que afecta a jóvenes. Debido a esto, se realiza una campaña de vacunación en mujeres en el año 1999, cuyo éxito quedó reflejado principalmente por la ausencia de casos de SRC a partir del año 2000.
Posteriormente, frente a la presencia de grupos susceptibles en el país (principalmente hombres), se producen brotes institucionales el 2005 con un bajo número de casos y en el 2007, un segundo brote de mayor magnitud y de extensión nacional que a la fecha, supera los 2500 casos confirmados.

Como medida de control de brote se han aplicado unas 50.000 dosis de vacuna entre los contactos de los casos. Además, a fines de este año se realizará una vacunación masiva dirigida a población susceptible (hombres entre 19 y 29 años), con lo que se espera contribuir a la eliminación de la rubéola y del SRC en Chile y América en el año 2010, según el acuerdo adoptado por los países Miembros de la Organización Panamericana de la Salud (OPS).Palabras clave:Brote de rubéola, estudio de susceptibles, vigilancia integrada sarampión - rubéola.

(1) Epidemióloga. Encargada Vigilancia Sarampión - Rubéola. Depto. Epidemiología. Ministerio de Salud. Chile. Mac Iver No 541. dgallego@minsal.cl

(2) Epidemióloga. Jefe Unidad de Vigilancia. Depto. Epidemiología. Ministerio de Salud. Chile.

(3) Epidemióloga. Depto. Epidemiología. Ministerio de Salud. Chile.

(3) Epidemióloga. Jefe Depto. Epidemiología. Ministerio de Salud. Chile.

(4) Epidemiólogo. Jefe de Unidad de Epidemiología. SEREMI Salud V Región. Valparaíso. Chile.

(5) Enfermera. Encargada Vigilancia Sarampión - Rubéola. Subdepartamento de Epidemiología. SEREMI Salud Metropolitana. Chile.

(6) Epidemiólogo. Coordinador Epidemiología de Campo. Subdepartamento de Epidemiología. SEREMI Salud Metropolitana. Chile.

(7) Tecnólogo Médico. Sección Virus Respiratorios y Exantemáticos. Subdepto. Virología Clínica. Instituto Salud Pública. Chile.

(8) Médico veterinario. Sección Virus Respiratorios y Exantemáticos. Subdepto. Virología Clínica. Instituto Salud Pública. Chile.

(9) Biólogo. Sección Virus Respiratorios y Exantemáticos. Subdepto. Virología Clínica. Instituto Salud Pública. Chile.

(10) Biólogo. Jefe Sección Genética Molecular, Laboratorio Biomédico Nacional de Referencia. Instituto Salud Pública. Chile.

(11) Bioquímico. Jefe Sección Virus Respiratorios y Exantemáticos. Subdepto. Virología Clínica. Instituto Salud Pública. Chile. 


\section{ANTECEDENTES}

La rubéola es una enfermedad de notificación obligatoria, según DS 158 . A partir del $1^{\circ}$ de julio de 2003 se integra esta vigilancia al sarampión, denominándose vigilancia integrada sarampión-rubéola. Esto implicó la notificación inmediata de los casos clínicos de rubéola, a través de un formulario único para ambas vigilancias, junto a la toma de una muestra serológica, a fin de confirmar el diagnóstico por laboratorio. Con ello, todos los casos sospechosos de rubéola notificados, son confirmados o descartados por el Instituto de Salud Pública (ISP), tanto para sarampión como para rubéola (Circular $\mathrm{N}^{\circ} 15 \mathrm{AD} / 38 \mathrm{del}$ 27/06/2003).

Respecto a la epidemiología de la enfermedad, antes de la introducción de la vacuna en forma programática en Chile (trivírica), la rubéola mostraba un ascenso sostenido con brotes cíclicos; situación que cambió en 1990 cuando se incorporó la vacuna en el calendario infantil. Así, desde esa fecha y hasta 1996, se observó un descenso paulatino de la incidencia de la enfermedad, afectando principalmente a menores de 10 años (Figura 1). Entre 1997 y 1998 se observó un repunte del número de casos en el país, con desplazamiento de la edad hacia adolescentes y adultos jóvenes ( $70 \%$ entre 10 y 29 años) ${ }^{1}$.

Frente a esta situación y a fin de evitar el SRC, en agosto de 1999 se realizó una campaña de inmunización dirigida a mujeres entre 10 y 29 años, alcanzando una cobertura del 99\%. Su impacto se reflejó en el descenso de las tasas de incidencia y en el cambio en la presentación de la edad de los casos. Así, la tasa disminuyó de 31 en 1998 a 11 por 100.000 hab. en 1999 , continuando con un descenso progresivo hasta lograr una incidencia de 1,9 por 100.000 hab. en el año 2002 (disminución de un 94\%) y una concentración del $68 \%$ de los casos en los menores de 5 años. En el 2003, la tasa se redujo a la mitad ( 0,8 por cien mil hab.), con 128 casos clínicos y, en el 2004 se confirmaron sólo 3 casos aislados en el país, cuando ya se había implementado la vigilancia integrada sarampiónrubéola y, con ello, la confirmación de todos los casos sospechosos por laboratorio ${ }^{1}$.

Por otra parte, previo a la campaña de vacunación de 1999, no existía en Chile un

Figura 1. Incidencia de rubéola en Chile años 1961 - 2007*(octubre)

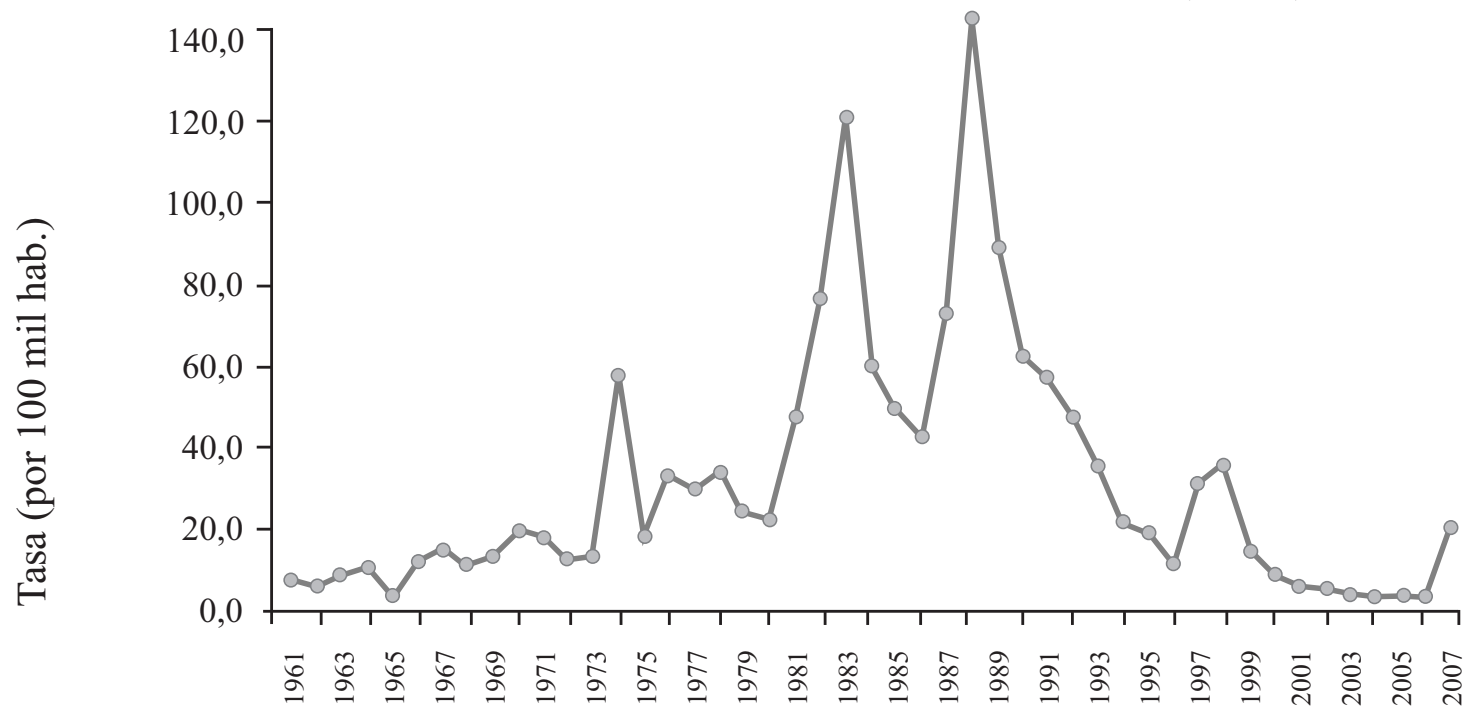

Fuente: DEIS - Epidemiología MINSAL

* Datos disponibles a la fecha de publicación de este artículo 
sistema de Vigilancia del SRC, el que se puso en marcha una vez concluida la campaña. A consecuencia del brote, en los años 1999 y 2000 se notificaron 18 casos de SRC (aislamiento viral genotipo 1E). Desde el año 2000, no se han informado nuevos casos de SRC en el país, según información basada en la vigilancia de SRC y TORCH, esta última realizada por el Instituto de Salud Pública (ISP) ${ }^{2}$.

Respecto a los brotes post campaña, entre enero-abril del 2005, se produce el primero de tipo Institucional, con 46 casos de rubéola y acotado a una sola región (Valparaíso). Afectó a hombres, pertenecientes a dos instituciones cerradas: la más afectada con 43 casos, entre 18 y 22 años y, posteriormente, otros 3 jóvenes pertenecientes a una universidad, sin nexo epidemiológico aparente entre ambas Instituciones. La confirmación etiológica fue realizada en 35 casos mediante serología en el ISP y el resto, por clínica y nexo epidemiológico.

Ese mismo año, se confirmó otro caso aislado en una mujer residente en la Región Metropolitana, sin nexo aparente con el brote ocurrido en la región de Valparaíso.

Ese año se realizó bloqueo epidemiológico, en una primera instancia, a las Especialidades afectadas tanto de la Armada, como de la Institución Académica. Posteriormente, se realizó una campaña de vacunación que incluyó a todas las personas pertenecientes a la Institución Naval asentados en la V Región (12.000 dosis de vacuna). Otras medidas que contribuyeron a evitar la dispersión comunitaria, fue el aislamiento de enfermos durante el período de transmisibilidad sintomático en Unidades de Enfermería de la Institución, la aplicación de medidas de confinamiento institucional y la recomendación de evitar el desplazamiento a otras regiones. Además, considerando que los jóvenes provenían de otras regiones del país, se realizó una investigación de los familiares y vacunación a los contactos, evitando la aparición de otros casos a nivel comunitario ${ }^{1}$.

Posteriormente, en abril de 2007 se confirmó el primer caso de rubéola que dio origen al brote que afecta prácticamente a todo el país y que, a fines de octubre, asciende a los 2.619 casos. Previo a su inicio, el Departamento de Epidemiología había realizado un estudio de susceptibles, identificando que el mayor riesgo se encontraba en la población masculina entre los 19 y 29 años, lo que resultó coincidente con los grupos de edad más afectados en el brote actual ${ }^{3}$.

Las coberturas de vacunación programática desde su introducción, se han mantenido cercanas al 95\%, meta óptima para lograr la eliminación de la enfermedad y evitar la aparición de brotes. Sin embargo, en los últimos años se ha observado un descenso progresivo, con las coberturas más bajas presentadas desde su incorporación al calendario de vacunación.

Por primera vez en el 2005, en el contexto de la $3^{\mathrm{a}}$ campaña de seguimiento de sarampión dirigida a niños entre 1 y 5 años, se incorporó la vacunas sarampión-rubéola (SR), a diferencia de la vacuna antisarampionosa (VAS) utilizada con anterioridad. Ese mismo año ya se había utilizado la vacuna SR para el control del brote Institucional en la región de Valparaíso y, actualmente, se continúa aplicando a los contactos como medida de bloqueo epidemiológico en casos de rubéola y sarampión ${ }^{3}$.

La rubéola se incluye como una enfermedad en vías de eliminación en el año 2003, tras el éxito en la interrupción de la transmisión del sarampión en las Américas (2002). Así, los países que integran la OPS acordaron eliminar la rubéola y el SRC para el año 2010. Para lograr esta meta, los países han ido ejecutando campañas de vacunación en adultos hombres y mujeres, posteriores a las realizadas en Chile (1999) y Brasil (2002). Estos países programaron la campaña sólo en mujeres, ya que el objetivo era prevenir el SRC y no eliminar la enfermedad como se acordó posteriormente en el año 2003.

A continuación se presenta la descripción del brote de rubéola que afecta al país desde comienzos del año 2007.

\section{OBJETIVO}

- Describir el brote actual en relación a tiempo, lugar y persona, en comparación al ocurrido en el año 2005.

- Describir los virus circulantes en nuestro país. 
- Describir las medidas utilizadas como medidas del control de brote.

\section{METODOLOGÍA}

Se realizó un estudio descriptivo, utilizando la información de las fichas de notificación inmediata que ingresan al software MESS** y verificación con bases de datos enviados por las regiones. Se estableció como Definición de Caso del brote: "todo hombre de 19 añoso más con sintomatología compatible de rubéola". Las mujeres o jóvenes de 18 años y menos, que presenten sintomatología compatible, deben ser confirmados por laboratorio.

Se alertó a todo el país mediante un comunicado y se realizó en una primera etapa, una búsqueda intensificada en todas las regiones que no habían confirmado casos, y, en las regiones afectadas desde el inicio del brote (V y RM), la búsqueda se focalizó en las
Instituciones donde se presentaban casos.

Se realizó una investigación epidemiológica exhaustiva de todos los primeros casos y sus contactos. Se realizó examen serológico para confirmación de laboratorio en una muestra representativa de casos y, en algunos de ellos, de tipo respiratoria, a fin de realizar aislamiento y genotipificación viral; todas las muestras fueron procesadas en ISP.

Como medida de control de brote, se vacunó a los contactos y poblaciones de mayor riesgo, de acuerdo a los criterios previamente definidos, que fueron modificándose de acuerdo a su evolución.

\section{RESULTADOS}

\section{Evolución del Brote}

El brote asciende a 2.619 casos confirmados hasta fines de octubre de $2007 \mathrm{y}$ actualmente, se extiende a todo el país, con excepción de la región

Figura 2. Casos de rubéola según región de ocurrencia Chile, marzo - octubre* 2007

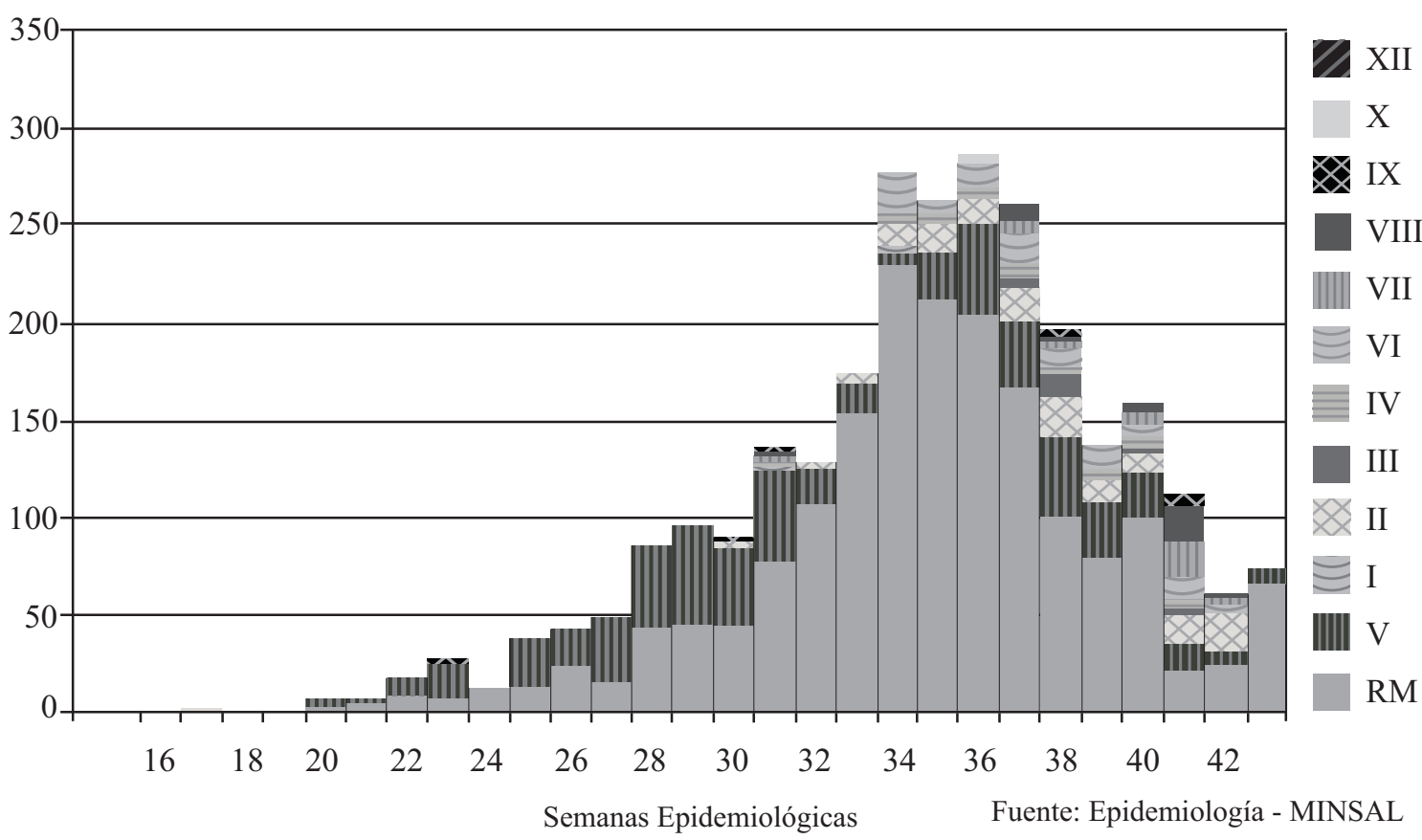

\footnotetext{
** Measles Elimination Surveillance -System; software en DOS creado por la OPS para
} la vigilancia integrada sarampión-rubéola en la Región de las Américas. 
de Aisén. Sin embargo, en la región de Los Lagos, se han reportado 3 casos aislados y, en la región de Magallanes, sólo un caso.

La curva epidémica muestra un ascenso sostenido, alcanzando el peak las semanas 34 a 37 con cerca de 300 casos semanales, según el número de casos reportados (Figura 2).

Respecto a la evolución, el día 13 de abril de 2007 el Instituto de Salud Pública confirmó el primer caso de rubéola en un joven de 26 años, estudiante de post grado, residente en el sector oriente de la Región Metropolitana; la fecha de primeros síntomas correspondió a marzo (semana epidemiológica 12). Posteriormente, aparece un segundo caso aislado, también en un joven trabajador de la RM. A mediados de abril se detecta el primer brote Institucional en una universidad, vacunándose a toda la facultad afectada. A partir de entonces, se detectaron brotes en otros establecimientos de educación superior y en otras Instituciones, aplicándose las medidas de control correspondiente. A fines de mayo se confirman los primeros casos en la región de Valparaíso, en distintos establecimientos de educación superior.

\section{Distribución Geográfica}

La primera etapa se focalizó principalmente en las regiones de Valparaíso y Metropolitana, posteriormente se confirmaron casos aislados las semanas 23 y 27, correspondientes a las regiones de Araucanía y Antofagasta, respectivamente. A partir de la semana 28 , se empiezan a sumar el resto de las regiones del país en distinta magnitud. Así, hasta el $10 \mathrm{de}$ agosto de 2007 se habían confirmado 350 casos y se habían aplicado 20.000 dosis de vacuna en actividades de control de brote.

Las regiones más afectadas corresponden a: Valparaíso (33,3 por cien mil hab.), Metropolitana (25 por cien mil hab.), Antofagasta (25 por cien mil hab.), Libertador Bdo. O'Higgins (12 por cien mil hab.), Atacama (9,5 por cien mil hab.) y Coquimbo $(6,8$ por cien mil hab.). El resto de las regiones presentan tasas entre 0,3 y 3,1 por cien mil habitantes, lo que representa a menos de 35 casos. (Figura 3 ).
Figura 3. Incidencia de rubéola según región. Chile, marzo - octubre* 2007

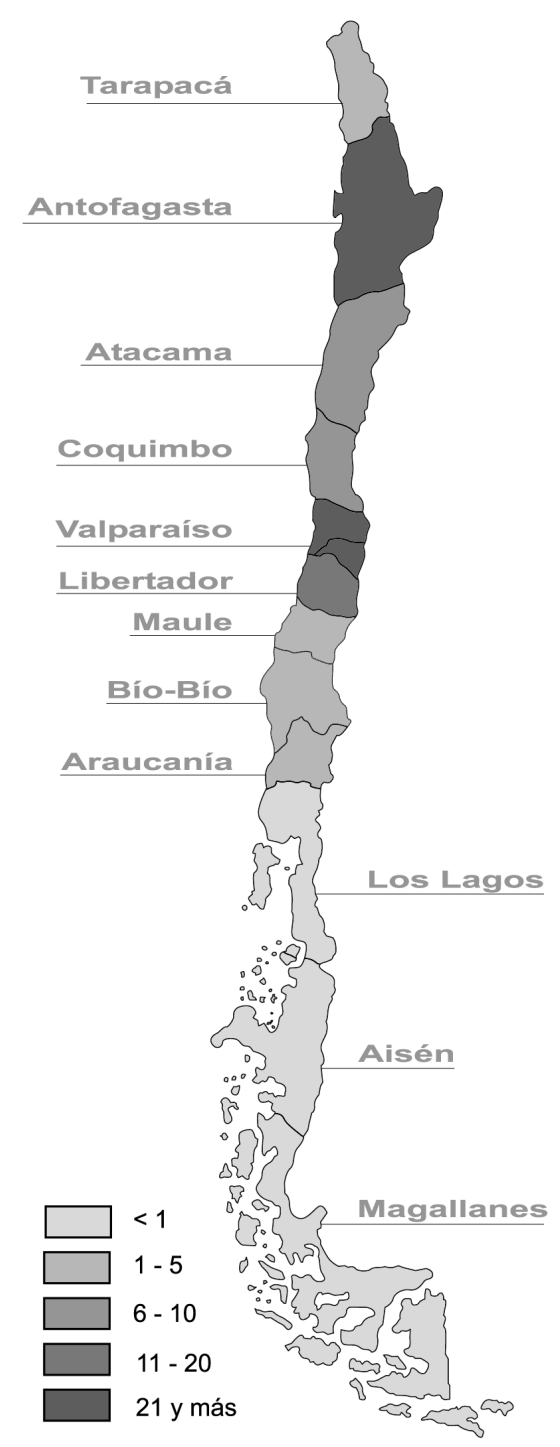

\section{Distribución por Sexo y Edad}

Los hombres son los más afectados (96\%). La mediana de edad es de 23 años, con un rango entre 8 meses y 74 años $(9$ casos en menores de 19 años). Las edades con mayor 
Figura 4. Tasa de Incidencia de rubéola en Hombres según edad Chile, Marzo - Octubre * 2007
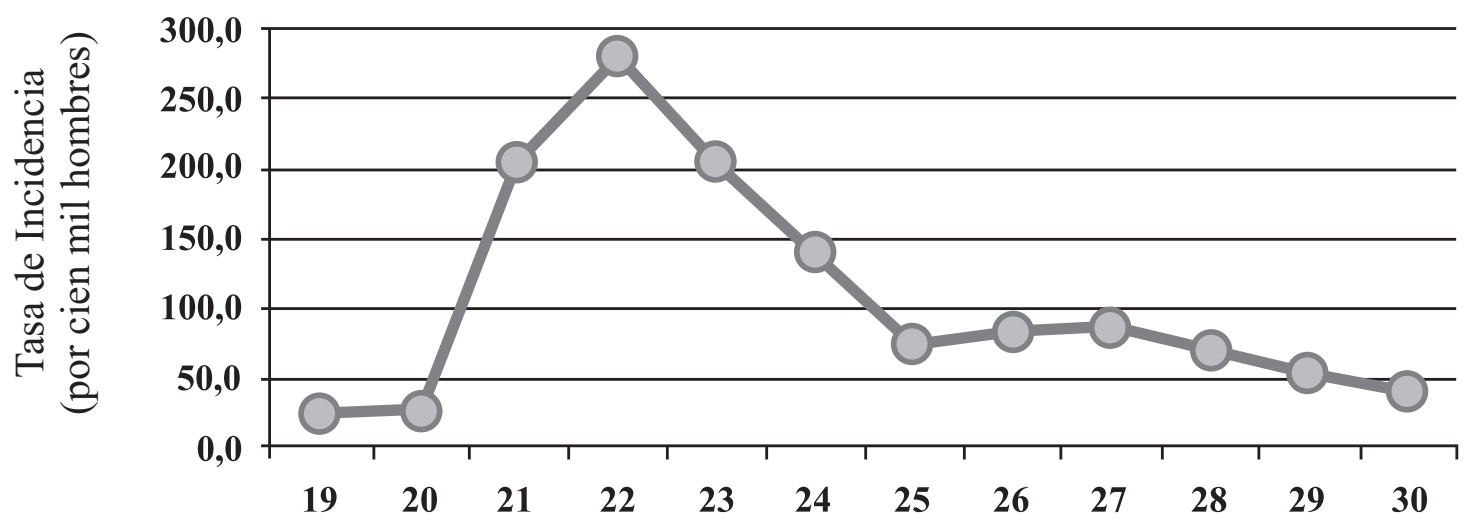

Fuente: Epidemiología - MINSAL

\section{Edades}

riesgo son entre los 21 y 24 años, con tasas por edad entre 141 y 283 por cien mil hombres (Figura 4).

\section{Aislamiento y Genotipificación Viral}

El resultado del secuenciamiento del virus rubéola realizado por el ISP fue el genotipo $2 \mathrm{~B}$, distinto al detectado en el brote de 2005 que correspondió al $1 \mathrm{C}$ que se encontraba en ese entonces en algunos países de América. Respecto al genotipo $2 \mathrm{~B}$, éste corresponde a una importación probablemente de Europa y que también es coincidente con el genotipo detectado en Brasil, país que se mantiene en brote desde el año 2006.

\section{Medidas de Control}

Respecto al brote actual, si bien se aplicaron medidas de bloqueo como la vacunación a las Instituciones afectadas, no fueron suficientes para el control oportuno del brote. La aplicación tardía de las medidas en los dos primeros casos confirmados, se debió a que el primer diagnóstico se orientó a un "cuadro de tipo alérgico". Además, no fue posible desarrollar medidas de salud pública complementarias para su control (aislamiento, confinamiento ni restricción de movimientos). Lo anterior, debido a que los primeros casos correspondieron a jóvenes residentes en la RM, que se desplazaban sin restricciones por la ciudad, a diferencia de lo ocurrido en el brote del 2005 donde los jóvenes se encontraban en régimen de internado en una Institución cerrada.

Con el fin de mejorar la pesquisa y actuar oportunamente para el control del brote, se implementaron las siguientes medidas en todo el país: alertar a los sistemas de vigilancia públicos y privados; notificar todos los casos sospechosos y solicitar muestra de sangre y respiratoria; realizar una detallada investigación de los casos confirmados buscando la probable fuente de infección y los contactos; aplicar vacuna sarampiónrubéola a todos los contactos inmediatos de los casos confirmados (aplicación de 50.000 dosis); realizar búsqueda activa en el resto del país para pesquisar otros casos en regiones no afectadas a la fecha; notificar a las redes internacionales de vigilancia y apoyar la programación de la vacunación masiva, dirigida al grupo de susceptibles.

Debido al brote de rubéola que afecta actualmente a nuestro país, entre el 5 y 30 de noviembre de 2007, el Ministerio de Salud se encuentra realizando una nueva campaña de vacunación dirigida a población susceptible.

\section{DISCUSIÓN}

El éxito de la primera campaña de vacunación realizada en mujeres en el año 1999 está dado por la ausencia de casos de SRC desde el año 2000. 
Debido a la existencia de población susceptible en Chile, principalmente hombres mayores de 19 años (al año 2007), se produjeron dos brotes posteriores a la campaña de vacunación de 1999: el 2005 que afectó a una Institución cerrada con dispersión a otra de tipo Académica, produciendo un número reducido de casos y, en el 2007, un brote de gran magnitud que afectó a instituciones, empresas y comunidad en general en un principio en las regiones de Valparaíso y Metropolitana y, posteriormente, a las otras regiones del país.

En el primer brote post campaña, la rapidez en el control se debió a que las acciones se desarrollaron oportunamente y que abarcaron no sólo vacunación, sino que principalmente medidas de salud pública posteriores, que impidieron la diseminación de la enfermedad. Esta fue la principal diferencia de lo ocurrido en el brote actual, dado que los primeros casos se detectaron tardíamente, afectando a jóvenes universitarios o trabajadores de la RM, con libre desplazamiento por la ciudad, lo que facilitó la transmisión entre otros susceptibles y extendiéndose, finalmente, a la mayoría de las regiones del país.

Si bien el brote a nivel nacional se encuentra en una fase de declinación, en algunas regiones se mantienen en etapa de meseta. La interrupción del brote será posible con la realización a fines de 2007, de la campaña de vacunación dirigida a la población susceptible (principalmente hombres entre los 19 y 29 años). Con la aplicación de esta estrategia, podremos además, concretar la eliminación de la rubéola en Chile y avanzar en la meta para las Américas.

La principal limitación en el estudio de este brote fue la notificación tardía, lo que retrasó las medidas de control a los primeros casos y contribuyó a la diseminación de la enfermedad, inicialmente, en dos de las principales ciudades del país. La oportunidad en la notificación depende de muchos factores, tales como la pesquisa precoz por parte de los clínicos, la coordinación entre los componentes de la vigilancia (clínica, laboratorio y epidemiología) y el funcionamiento de la red de vigilancia tanto pública como privada.
Respecto a los logros, en Chile ha habido grandes avances en materia de aislamiento y genotipificación viral, a través del Instituto de Salud Pública, primero con el sarampión y ahora con la rubéola. Se han detectado 3 genotipos virales de rubéola: 1E (brote 1998-99), 1C (brote 2005) y 2B (brote 2007); esto podría indicar que los genotipos del grupo 1 corresponderían a los circulantes en el país, ya que son propios de América. El genotipo 2B es el mismo que circula en Europa y que se introdujo a América durante este último tiempo, ya que se ha identificado en Chile y Brasil, país que se encuentra en brote desde el año 2006, con más de cuatro mil casos reportados a la fecha ${ }^{4}$.

Para mantener los logros alcanzados hasta la fecha y eliminar la rubéola y el SRC en los plazos fijados, es necesario mantener una vigilancia activa de casos exantemáticos y realizar estudios de genotipificación viral, asimismo, mantener coberturas elevadas (95\%) en todas las comunas, mediante los programas de vacunación rutinaria y en campañas.

Agradecimientos:

A los equipos de Epidemiología de las SEREMI y profesionales de los Establecimientos de Salud del país, que han trabajado activamente en la investigación y control del brote.

\section{REFERENCIAS}

1. GOBIERNO DE CHILE. Ministerio de Salud. División de Planificación Sanitaria. Departamento de Epidemiología. Sarampión y Rubéola, en vías de eliminación en la Región de las Américas. El Vigía 2005; 9(23):40-43.

2. GOBIERNO DE CHILE. Ministerio de Salud. División de Salud de las Personas. Departamento de Epidemiología. La Campaña de Vacunación contra la Rubéola en Chile, año 2000.

3. GOBIERNO DE CHILE. Ministerio de Salud. División de Planificación Sanitaria. Departamento de Epidemiología. Estrategias de Eliminación de la Rubéola en Chile. El Vigía 2007; 10(24):en vías de publicación.

4. ORGANIZACIÓN PANAMERICANA DE LA SALUD. Área de Salud Familiar y Comunitaria. Unidad de Inmunizaciones. Boletín Semanal de Sarampión / Rubéola. 2005; 13(42).

Usted puede comentar éste y otros artículos publicados en la Revista Chilena de Salud Pública, enviando un correo electrónico a revistasp@med.uchile.cl 